two groups and whether this might account for the different immunological reactivities of the two populations.

In conclusion, we believe that in very high risk groups the combined use of in situ hybridisation and gene amplification by polymerase chain reactions is a necessary diagnostic tool for identifying asymptomatic seronegative carriers of HIV-I infection. Furthermore, viral isolation and characterisation will eventually explain whether the lack of immunological recognition in seronegative infected subjects at risk is due to the presence of peculiar viral isolates-for example, defective proviruses-or to a different viral cytotropism, or to both.

This work was supported by the Swedish Medical Research Council (MFR) (grant B89-16H-04A), the US Army Medical Research and Development Command (grant DAMD 17-86G-6039), and the Italian National Research Council (Cnr). PR was a visiting scientist at the Karolinska Institute. We thank Dr R C Gallo for providing BH 10 clones; Dr F Wong-Staal, of the National Institutes of Health, Bethesda, Maryland, for the pSP64 plasmid and pBH10-R3 DNA; and Dr A Buchbinder, National Institutes of Health, Bethesda, for the SK70 oligonucleotide probe.

1 Varmus H. Retroviruses. Science 1988;240:1+27-35

2 Fauci $\mathrm{AS}$. The human immunodeficiency virus: infectivity and mechanisms of pathogenesis. Science 1988;233:617-22.
3 Ranki A, Valle SI, Krohn M, et al. Long latency precedes overt seroconversion in sexually transmitted human-immunodeficiency-virus infection. Lancet 1987;ii:589-93.

+ Goetz DW, Hall SE, Harbizon RW, Reid MJ. Pediatric acquired immunodeficiency syndrome with negative human immunodeficiency virus antibody response by ELISA and western blot. Pediatrics 1988;81:356-9.

5 Hames BD, Higgins SJ. Nucleic acid hybridization. A practical approach. Washington, DC: IRL Press, 1985:179.

6 Ou CY, Kwok S, Mitchell SW, et al. DNA amplification for direct detection of HIV-1 1)NA of peripheral blood mononuclear cells. Science 1988;239:295-7.

7 Saiki RK, Gelfand DH, Stoffel S, et al. Primer-directed enzymatic amplification of DNA with a thermostable DNA polymerase. Science 1988;239: 487.91.

8 Pezzella M, Pezzella F, Gali $\mathrm{C}$, et al. In situ hybridization of human immunodeficiency virus (HTLV III) in cryostat sections of lymph nodes of lymphadenopathy syndrome patients. F Med Virol 1987;22:135-42.

9 Hahn BH, Shaw (FM, Anya SK, et al. Molecular cloning and characterization of the HTLV III virus associated with AIDS. Nature 1984;312:166-9.

10 Harper ME, Marselle LM, Gallo RC, Wong-Staal F. Detection of lymphocytes expressing human T-lymphotropic virus type III in lymph nodes in peripheral blood from infected individuals by in situ hybridization. Proc Nall Acad Sci L'SA 1986;83:772-6.

11 Curran JW, Jaffe HW, Hardy AM, el al. Epidemiology of human immunodeficiencr virus infection and AIDS in the United States. Science 1988:239: $610-6$

12 Loche M, Mach B. Identification of HIV-infected seronegative individuals by a direct diagnostic test based on hybridisation to amplified viral DNA. a direct diagnostic tes

13 Amadori A, De Rossi A, Giaquinto C, et al. In vitro production of human immunodeficiency virus specific antibody in children at risk of AIDS. Lancet
imadonation of human immunodeficic 1988 ;ii: $852-4$.

1t Laure F, Courgnaud $V$, Rouzioux $C$, et al. Detection of HIV-1 DNA in infants and children by means of the polymerase chain reaction. Lancet 1988;ii: $538-41$

15 Gartner S, Markovitz D, Markovitz DM, et al. The role of mononuclear phagocytes in HTLV III/LAV infection. Science 1986;233:215-9.

Accepted 9 fanuary 1989
Epidemiology and Public Health Research Unit, University of Surrey, Guildford, Surrey GU2 5XH

$\mathrm{R}$ Balarajan, $\mathrm{FFCM}$, director $\mathrm{V}$ Soni Raleigh, PHD, senior research fellow

\section{Medical Statistics} Division, Office of Population Censuses and Surveys, London WC2B 6JP

B Botting, BSC, statistician

Correspondence to: Dr Balarajan.

\title{
Sudden infant death syndrome and postneonatal mortality in immigrants in England and Wales
}

\author{
R Balarajan, V Soni Raleigh, B Botting
}

\section{Abstract}

To examine ethnic differences in postneonatal mortality and the incidence of sudden infant death in England and Wales during 1982-5 records were analysed, the mother's country of birth being used to determine ethnic group. Postneonatal mortality was highest in infants of mothers born in Pakistan $(6 \cdot 4 / 1000$ live births) followed by infants of mothers born in the Caribbean (4.5) and the United Kingdom and Republic of Ireland $(4 \cdot 1)$. Crude rates were lower in infants of mothers born in India (3.9/1000), east and west Africa (3.0), and Bangladesh (2.8) than in infants of mothers born in the United Kingdom despite less favourable birth weights. Mortality ratios standardised separately for maternal age, parity, and social class were significantly higher in infants of mothers born in Pakistan and lower in those of mothers born in Bangladesh. The ratio for infants of Caribbean mothers was significantly higher when adjusted for maternal age. Ratios for infants of Indian and east African mothers did not show significant differences after standardisation. An important finding was a low incidence of sudden infant death in infants of Asian origin. This was paralleled by lower mortality from respiratory causes. During $1975-85$ postneonatal mortality in all immigrant groups except Pakistanis fell to a similar or lower rate than that in the United Kingdom group; Pakistanis showed a persistent excess. During 1984-5 several immigrant groups (from the Republic of Ireland, India, west Africa, and the Caribbean) recorded an increase in postneonatal mortality.

Surveillance of postneonatal mortality among ethnic communities should be continued, and re- search is needed to identify the causes underlying the differences.

\section{Introduction}

Most of the fall in infant mortality since the 1970s has been due to a steady fall in neonatal mortality rather than postneonatal mortality.' During 1985-6 postneonatal mortality in fact increased from $3 \cdot 9 / 1000$ live births to $4 \cdot 3 / 1000$, leading to a rise in overall infant mortality. ${ }^{2}$ About $42 \%$ of all infant deaths occur in the postneonatal period, with sudden infant death the main cause. ${ }^{3}$ Concern about the slow fall in postneonatal mortality and the major contribution of sudden infant death prompted a multicentre inquiry by the Department of Health and Social Security into postneonatal deaths during 1976-9 in selected areas of England and Wales. ${ }^{+}$The study recommended improvements in health care services and emphasised the importance of educating parents in child care. Ethnic differences in postneonatal mortality and the incidence of sudden infant death have not previously been examined in detail nationally. We analysed postneonatal mortality in England and Wales by the mother's country of birth during 1982-5, the years for which detailed tables were available. We also intend to examine data for subsequent years in view of a recent upward trend in postneonatal mortality. ${ }^{2}$

\section{Subjects and methods}

Since 1975 the Office of Population Censuses and Surveys has linked records of births and deaths of infants under 1 year old. ${ }^{5}$ Data from these records were 
aggregated for the years $1982-5$ to examine postneonatal mortality in England and Wales by mother's country of birth. Variations in postneonatal mortality by maternal age, parity (defined as the number of previous live births and stillbirths), social class of father, birth weight, and cause of death were examined for mothers born in the United Kingdom, the Republic of Ireland, India, Bangladesh, east and west Africa, the Caribbean, and Pakistan. The social class groups studied were: I, professional and managerial; II, intermediate; IIIN, skilled non-manual; IIIM, skilled manual; IV, partly skilled; and V, unskilled. Because the numbers of deaths were low in some categories the groups were aggregated into non-manual (classes I, II, and IIIN) and manual (classes IIIM, IV, and V).

We could not examine interactions between the maternal variables and their relative contribution to ethnic differences in postneonatal mortality. We therefore computed standardised postneonatal mortality ratios, standardising separately for maternal age (by five year age groups), parity, and social class, with the respective rates (1982-5) for mothers born in the United Kingdom as the standard. We calculated 95\% confidence intervals when appropriate. As data relating to parity and social class were confined to births within marriage the ratios standardised for these variables were similarly restricted. Postneonatal mortality among births within marriage and outside marriage was examined separately. We did not try to standardise by birth weight in view of the distinct differences between immigrant groups in distributions of weight. We also examined trends in postneonatal mortality by mother's country of birth during 1975-85 on the basis of three year moving averages. Postneonatal mortality was expressed as deaths of infants aged between 28 days and 1 year per 1000 live births.

The analysis by cause of death was based on International Classification of Diseases (ICD) codes and included sudden death from unknown causes (ICD 798 ); virtually all the infant deaths in this category were classified as ICD 7980, the sudden infant death syndrome. ${ }^{\circ}$ We therefore interpreted the findings in our analysis on sudden death from unknown causes as referring to the sudden infant death syndrome.

Country of birth is a reasonably good substitute for ethnic origin of women of childbearing age as people of British origin born overseas belong primarily to older generations. The only notable exceptions are east
African immigrants, most of whom are of Indian ethnic origin. ${ }^{8}$ A problem associated with this method of classification is that second generation immigrant mothers are classified as born in the United Kingdom rather than overseas. Their numbers, however, are as yet too small to affect greatly the results for those born in the United Kingdom. ${ }^{9}$ We believe that classification by mother's country of birth is, for the present, a legitimate means of examining ethnic differences in mortality.

\section{Results}

Of the 10372 postneonatal deaths in England and Wales during 1982-5, 9077 were of infants born to mothers born in the United Kingdom and 1295 of infants born to mothers born overseas. The groups according to country of birth examined in this study accounted for $96 \%$ of all postneonatal deaths during 1982-5. Postneonatal mortality per 1000 live births (table I) was highest in infants of mothers born in Pakistan (6.4) followed by infants of mothers born in the Caribbean (4.5), the United Kingdom (4.1), and the Republic of Ireland $(4 \cdot 1)$. Infants of mothers born in India (3.9), Africa (3.0), and Bangladesh (2.8) had a lower mortality than infants of mothers born in the United Kingdom.

\section{MOTHER'S AGE}

Ratios standardised for maternal age (table I) were highest in Pakistani infants (161, 95\% confidence interval 145 to 179$)$ and Caribbean infants $(123,101$ to $150)$. The lowest ratios were seen among Bangladeshi infants $(68,51$ to 91) and African infants, though only the ratio in the Bangladeshi infants reached statistical significance. Age specific rates for Pakistani infants for all maternal ages were higher than those for other groups of Asian origin (Indians, Bangladeshis, and east Africans), being $1 \cdot 5-2 \cdot 3$ times greater than those in the United Kingdom group except in mothers under 20 years old.

\section{PARITY}

At every parity mortality was highest in infants of mothers born in Pakistan, being higher than that for other infants of Asian origin. The ratio standardised for parity (table I) was significantly higher in Pakistani

TABLE I - Postneonatal mortality by mother's country of birth, England and Wales, 1982-5. (Observed numbers of deaths in parentheses)

\begin{tabular}{|c|c|c|c|c|c|}
\hline \multirow[b]{2}{*}{ Mother's country of birth } & \multirow{2}{*}{$\begin{array}{l}\text { Postneonatal } \\
\text { mortality } \\
\text { (deaths/1000 } \\
\text { live births) }\end{array}$} & \multicolumn{2}{|c|}{ Ratios standardised for mother's age ${ }^{\star}$} & \multicolumn{2}{|c|}{ Ratios standardised for parity $†$} \\
\hline & & Ratio & $\begin{array}{l}95 \% \text { Confidence } \\
\text { interval }\end{array}$ & Ratio & $\begin{array}{l}95 \% \text { Contidence } \\
\text { interval }\end{array}$ \\
\hline United Kingdom & $4 \cdot 1(9077)$ & $100(9077)$ & & $100(6621)$ & \\
\hline Republic of Ireland & $4 \cdot 1$ (111) & 118 (111) & 9210134 & $93 \quad(81)$ & 7710112 \\
\hline India & 3.9 (181) & 101 (181) & 87 to 117 & $103(180)$ & 89 to 119 \\
\hline Bangladesh & $2 \cdot 8 \quad 44$ & $68 \quad 44$ & 51 to 91 & $62 \quad(43)$ & 46 to 83 \\
\hline East Africa & $3 \cdot 0 \quad 83)$ & (83) & 67 to 103 & (79) & 67 to 103 \\
\hline West Africa & 3.0 & (35) & 60 to 116 & (28) & 52 to 102 \\
\hline Caribbean countries & 4.5 & $123 \quad 95$ & 101 to 150 & $95 \quad(40)$ & 78 to 116 \\
\hline Pakistan & $6.4 \quad(343)$ & $161 \quad(343)$ & 145 to 179 & $147(341)$ & 132 to 163 \\
\hline
\end{tabular}

*Based on all births. †Legitimate births.

TABLE II - Postneonatal mortality by mother's country of birth, England and Wales, 1982-5. (Observed numbers of deaths in parentheses)

\begin{tabular}{|c|c|c|c|c|}
\hline \multirow[b]{2}{*}{ Mother's country of birth } & \multicolumn{2}{|c|}{ Ratios standardised for social class* } & \multicolumn{2}{|c|}{ Postneonatal mortality (deaths/1000 live births) } \\
\hline & Ratio & $95 \%$ Confidence interval & Legitimate births & Illegitimate births \\
\hline United Kingdom & $100(6621)$ & & $3 \cdot 6(6621)$ & $6 \cdot 2(2456)$ \\
\hline Republic of Ireland & $107 \quad 81$ & 89 to 129 & $3 \cdot 7 \quad(81)$ & $6.4 \quad(30)$ \\
\hline India & $106(180)$ & 92 to 123 & $4.0 \quad(180)$ & $1 \cdot 4$ \\
\hline Bangladesh & $68 \quad 43$ & 51 to 91 & $2 \cdot 8 \quad(43)$ & $14 \cdot 5$ \\
\hline East Africa & $84 \quad 79$ & 68 to 104 & $3 \cdot 0 \quad(79)$ & $5 \cdot 3$ \\
\hline West Africa & $67 \quad(28)$ & 48 to 93 & $2 \cdot 9 \quad(28)$ & $3 \cdot 5$ \\
\hline Caribbean countries & $108 \quad(40)$ & 88 to 132 & $3 \cdot 7 \quad(40)$ & (55) \\
\hline Pakistan & 158 & 142 to 176 & $6 \cdot 4(341)$ & $5 \cdot 2$ \\
\hline
\end{tabular}

^Legitimate births. 
infants $(147,132$ to 163). Ratios were lower in Bangladeshi and African infants, though reaching significance only in Bangladeshi infants (62, 46 to 83 ). Births outside marriage constituted half of live births to Caribbean mothers. Other groups with a sizable proportion of births outside marriage included mothers from the United Kingdom (18\%), the Republic of Ireland $(18 \%)$, and west Africa $(17 \%)$. The ratios standardised for parity therefore did not include a substantial proportion of births in these groups.

\section{SOCIAL CLASS}

In all ethnic groups postneonatal mortality was higher in the manual than the non-manual social classes. Babies born to mothers from Pakistan showed the highest rates in most social classes. Postneonatal mortality ratios adjusted for social class (table II) were significantly higher in Pakistani infants $(158,142$ to $176)$ and lower in west African $(67,48$ to 93$)$ and Bangladeshi $(68,51$ to 91$)$ infants. As social class was not available for births outside marriage the ratios adjusted for class did not include a sizable proportion of births to mothers born in the United Kingdom, the Republic of Ireland, west Africa, and the Caribbean. In these groups mortality among infants born outside marriage was $1 \cdot 2-1 \cdot 7$ times greater than mortality among infants born within marriage. Mortality among infants born outside marriage was lower for mothers born in west Africa or the Caribbean (3.5/1000 and $5 \cdot 2 / 1000$ respectively) than for mothers from the

TABLE: III-Percentage distribution of birth weight by mother's country of birth, England and Wales, 1982-5

\begin{tabular}{|c|c|c|c|c|c|c|}
\hline \multirow[b]{2}{*}{ Mother's country of birth } & \multirow[b]{2}{*}{$\begin{array}{l}\text { Total No } \\
\text { of births }\end{array}$} & \multicolumn{5}{|c|}{ Birth weight (g) } \\
\hline & & $<2500$ & $\begin{array}{l}2500- \\
2999\end{array}$ & $\begin{array}{l}3000- \\
3499\end{array}$ & $\begin{array}{l}3500- \\
3999\end{array}$ & $\geqslant 4000$ \\
\hline United Kingdom & 2238096 & $6 \cdot 8$ & $17 \cdot 8$ & $38 \cdot 4$ & $28 \cdot 0$ & $9 \cdot 0$ \\
\hline Republic of Ireland & 26908 & $6 \cdot 4$ & $15 \cdot 9$ & $36 \cdot 5$ & $30 \cdot 0$ & $11 \cdot 2$ \\
\hline India & 46225 & $11 \cdot 4$ & $31 \cdot 5$ & $38 \cdot 5$ & $15 \cdot 4$ & $3 \cdot 3$ \\
\hline Bangladesh & 15783 & $10 \cdot 4$ & $32 \cdot 2$ & $39 \cdot 6$ & $14 \cdot 6$ & $3 \cdot 2$ \\
\hline East Africa & 27509 & $13 \cdot 3$ & $34 \cdot 6$ & $36 \cdot 1$ & $13 \cdot 4$ & $2 \cdot 6$ \\
\hline West Africa & 11725 & $8 \cdot 0$ & $19 \cdot 3$ & $40 \cdot 0$ & $24 \cdot 8$ & $7 \cdot 9$ \\
\hline Caribbean countries & $21+38$ & $9 \cdot 9$ & $23 \cdot 0$ & $39 \cdot 5$ & $21 \cdot 6$ & $6 \cdot 0$ \\
\hline Pakistan & $54+59$ & $9 \cdot 7$ & $26 \cdot 2$ & $39 \cdot 6$ & $19 \cdot 4$ & $5 \cdot 2$ \\
\hline
\end{tabular}

United Kingdom $(6 \cdot 2 / 1000)$ or the Republic of Ireland $(6 \cdot 4 / 1000)$.

\section{BIRTH WEIGHT}

Birthweight distributions ere similar in the groups from the United Kingdom and the Republic of Ireland but different in the immigrant groups (table III). Mothers born in India, Bangladesh, and east Africa had a higher proportion of babies weighing under $3000 \mathrm{~g}$ than other groups. Pakistani infants had higher birth weights than other infants of Asian origin but not than infants born to mothers born in the United Kingdom.

At most birth weights mortality was highest in Pakistani infants, being considerably higher than that in other Asian infants (table IV). Indian, Bangladeshi, and east African infants had a lower mortality than infants of mothers born in the United Kingdom at every birth weight. Differences in mortality between groups were large at lower birth weights (range $9 \cdot 2-19 \cdot 6$ at $<2500 \mathrm{~g}$ ) and fell with increasing birth weight (range $1 \cdot 3-3 \cdot 3$ at $3500-3999 \mathrm{~g}$ ).

\section{CAUSE OF DEATH}

Table V shows postneonatal mortality for selected causes of death. Sudden death from unknown causes (ICD 798) was the leading cause of postneonatal death in the United Kingdom, Republic of Ireland, and Caribbean groups, accounting for $42 \%, 43 \%$, and $32 \%$ respectively. In Indians, Bangladeshis, Africans, and Pakistanis congenital anomalies (ICD 740-759) were the main cause of death, responsible for $27-36 \%$ of postneonatal deaths.

Infants of Asian and African origin had much lower rates of sudden infant death than infants of mothers born in the United Kingdom or Republic of Ireland. Indian, Bangladeshi, and African infants also had a lower mortality from respiratory diseases (ICD 460-519), which was marginally higher in Pakistani infants than in the United Kingdom group. Infants born of mothers from the Caribbean showed smaller differences from the United Kingdom group in rates of sudden infant death and mortality from respiratory diseases. Differences between the indigenous and

TABLE IV-Postneonatal mortality (deaths/1000 live births) by birth weight and mother's country of birth, England and Wales, $1982-5$. (Observed numbers of deaths in parentheses) ${ }^{\star}$

\begin{tabular}{|c|c|c|c|c|c|c|}
\hline \multirow[b]{2}{*}{ Mother's country of birth } & \multirow[b]{2}{*}{ Total } & \multicolumn{5}{|c|}{ Birth weight (g) } \\
\hline & & $<2500$ & $2500-2999$ & $3000-3499$ & $3500-3999$ & $\geqslant 4000$ \\
\hline United Kingdom & $4 \cdot 1(9077)$ & $14 \cdot 4(2049)$ & $5 \cdot 2(2042)$ & $3 \cdot 3(2767)$ & $2 \cdot 5(1573)$ & $2 \cdot 2(442)$ \\
\hline Republic of Ireland & $4 \cdot 1 \quad(111)$ & $16 \cdot 2 \quad(26)$ & $5 \cdot 5 \quad(23)$ & $3 \cdot 4 \quad(33)$ & $2 \cdot 1 \quad(17)$ & $3 \cdot 4(10)$ \\
\hline India & $3.9(181)$ & $12 \cdot 6 \quad(63)$ & $3.0 \quad(43)$ & $3 \cdot 1 \quad 54$ & $2 \cdot 4 \quad(17)$ & $0.7 \quad(1)$ \\
\hline Bangladesh & $2 \cdot 8 \quad(44)$ & $9 \cdot 7 \quad(15)$ & $3.4 \quad(17)$ & (5) & (3) & \\
\hline East Africa & $3.0 \quad(83)$ & $9 \cdot 2 \quad(32)$ & (21) & (19) & $2 \cdot 2$ & 1.4 \\
\hline West Africa & $3 \cdot 0 \quad(35)$ & $17 \cdot 0 \quad(15)$ & (1) & (11) & (6) & $2 \cdot 2$ \\
\hline Caribbean countries & $4.5 \quad(95)$ & $15 \cdot 8 \quad(32)$ & (18) & $2 \cdot 9 \quad(24)$ & (15) & 0.8 \\
\hline Pakistan & $6 \cdot 4(343)$ & $19 \cdot 6$ & (89) & $5 \cdot 3(112)$ & (34) & $3 \cdot 3$ \\
\hline
\end{tabular}

ॠData not available for all births.

TABLE V-Postneonatal mortality (deaths/1000 live births) by cause of death and mother's country of birth, England and Wales, 1982-5. (Observed number of deaths in parentheses)

Cause of death

\begin{tabular}{|c|c|c|c|c|c|c|c|}
\hline \multirow[b]{2}{*}{ Mother's country of birth } & \multirow[b]{2}{*}{$\begin{array}{c}\text { Total } \\
\text { (all causes) }\end{array}$} & \multicolumn{6}{|c|}{ Cause of death } \\
\hline & & $\begin{array}{l}\text { Diseases of } \\
\text { respiratory } \\
\text { system } \\
\text { (ICD 460-519) }\end{array}$ & $\begin{array}{c}\text { Congenital } \\
\text { anomalies } \\
\text { (ICD 740-759) }\end{array}$ & $\begin{array}{c}\text { Perinatal } \\
\text { conditions } \\
(\text { ICD 760-779) }\end{array}$ & $\begin{array}{l}\text { Sudden death } \\
\text { (ICD 798) }\end{array}$ & $\begin{array}{c}\text { Accidents } \\
\text { (ICD 800-999) }\end{array}$ & Other \\
\hline United Kingdom & $4 \cdot 1(9077)$ & $0.7(1529)$ & $0.7(1664)$ & $0 \cdot 2(472)$ & $1.7(3831)$ & $0 \cdot 2(339)$ & $0 \cdot 6(1242)$ \\
\hline Republic of Ireland & $4 \cdot 1$ (111) & $0.6 \quad(17)$ & $0.9 \quad(23)$ & $0 \cdot 3 \quad(8)$ & $1.8 \quad(48)$ & $0 \cdot 1 \quad(3)$ & $0 \cdot 4 \quad(12)$ \\
\hline India & $3.9(181)$ & $0.3 \quad 16$ & $1.0 \quad(48)$ & $0 \cdot 3 \quad(15)$ & $0.8 \quad(38)$ & $0 \cdot 3 \quad(15)$ & $1 \cdot 1 \quad(49)$ \\
\hline Bangladesh & $2 \cdot 8 \quad(44)$ & 0.4 & $1.0 \quad(16)$ & $0 \cdot 3 \quad(5)$ & $0 \cdot 3 \quad$ (4) & $0 \cdot 1 \quad(2)$ & $0 \cdot 6 \quad(10)$ \\
\hline East Africa & $3.0 \quad 83)$ & (13) & $0.9 \quad(25)$ & (8) & (18) & $0 \cdot 2$ & 0.5 \\
\hline West Africa & $3.0 \quad(35)$ & $0 \cdot 3$ & $0.9 \quad$ (11) & $0 \cdot 3 \quad 4$ & (7) & & $0 \cdot 8$ \\
\hline Caribbean countries & $4.5 \quad(95)$ & (18) & $0.8 \quad 18)$ & 0.6 (12) & (30) & $0 \cdot 2 \quad(4)$ & $0 \cdot 6 \quad$ (13) \\
\hline Pakistan & $6.4(343)$ & (45) & $2 \cdot 0(106)$ & $0.4(20)$ & (47) & $0 \cdot 2 \quad(10)$ & $2 \cdot 1 \quad(115)$ \\
\hline
\end{tabular}

ICD = International Classification of Diseases. 


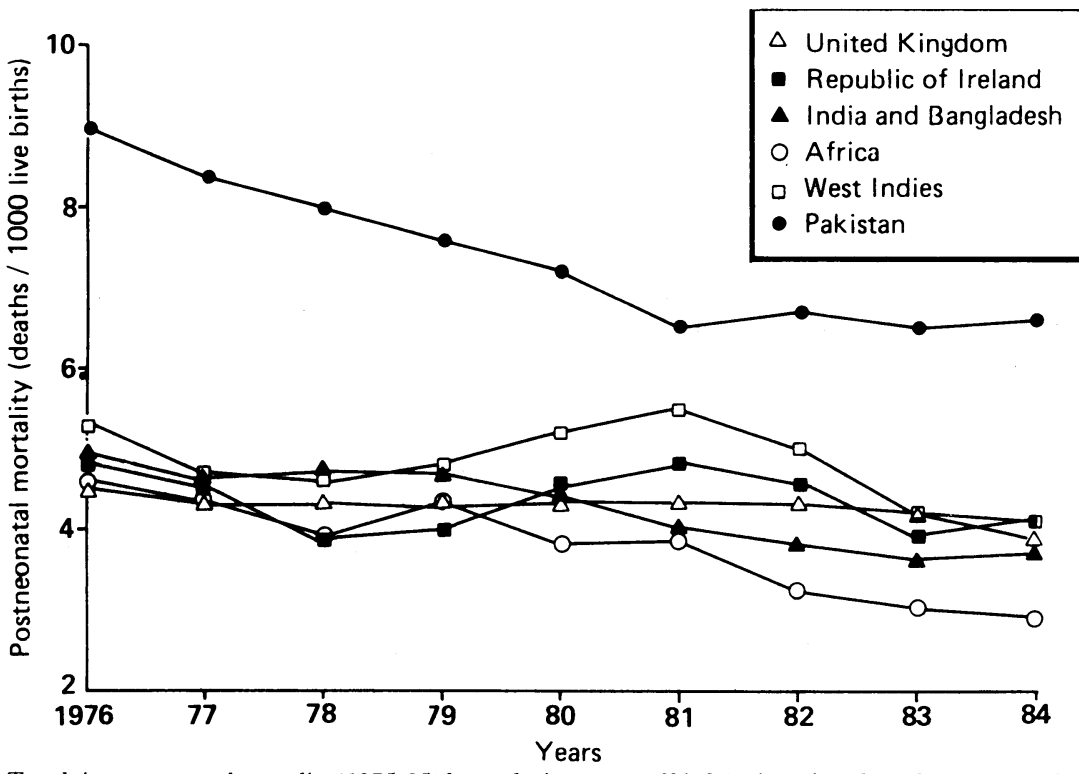

Trends in postneonatal mortality (1975-85) by mother's country of birth (points plotted are three year moving averages)

immigrant groups in the rate of accidental deaths were small. Mortality from congenital anomalies was, however, higher in Asian infants, particularly Pakistanis. Mortality from perinatal conditions (ICD 760-779) was marginally higher in immigrant groups. Postneonatal mortality from other causes was higher in Pakistani and Indian infants; further details of specific causes included in this category were not available.

\section{TRENDS DURING 1975-85}

The figure shows trends in postneonatal mortality during $1975-85$ based on three year moving averages. For this part of the analysis data on mothers from India and Bangladesh were combined, as were data on mothers from east and west Africa, because data for earlier years were not readily available for these groups separately.

In infants of mothers born in the United Kingdom postneonatal mortality was relatively unchanged from the mid-1970s until 1983, when it fell slightly. The rate in infants of mothers from the Republic of Ireland did not show any consistent trend. Mortality in Indian and Bangladeshi infants fell from about $5 \cdot 0 / 1000$ live births in 1975 to an average of $3 \cdot 7 / 1000$ in $1983-5$. African infants showed the largest fall of any group, with rates falling from over $5 \cdot 0 / 1000$ in the mid-1970s to an average of $2 \cdot 9 / 1000$ for $1983-5$. Changes in mortality in Caribbean infants were not consistent, but the overall trend was downwards. The highest mortality throughout was seen in Pakistani infants; their postneonatal rate showed a consistent fall up to the early 1980s but no change in subsequent years. The ratio of mortality in Pakistani to United Kingdom infants thus fell from 2.0 in the mid-1970s to 1.6 in the mid-1980s. During 1976-9 differences in postneonatal mortality among groups other than Pakistanis were fairly small, with most immigrant groups showing a somewhat higher mortality than the United Kingdom group. By 1984 postneonatal mortality in immigrant groups other than Pakistanis was similar to or lower than that for mothers born in the United Kingdom.

Yearly data for England and Wales showed that postneonatal mortality increased marginally by $0 \cdot 1 / 1000$ live births during $1984-5$. In some immigrant groups the increase was considerably larger: $1 \cdot 3 / 1000$ in those from the Republic of Ireland, $1 \cdot 0 / 1000$ in Indians, $1 \cdot 0 / 1000$ in west Africans, and $2 \cdot 0 / 1000$ in Caribbeans. Postneonatal mortality fell by $0 \cdot 3 / 1000$ in Pakistanis. In infants of mothers born in the United Kingdom postneonatal mortality remained constant during 1984-5.

\section{Discussion}

Our analysis showed considerable ethnic variations in postneonatal mortality in England and Wales. The patterns of these variations contrast with the patterns reported for the perinatal period ( $\mathrm{R}$ Balarajan, B Botting, unpublished data). During 1982-5 perinatal mortality in all immigrant groups was higher than that in the groups from the United Kingdom and the Republic of Ireland, being $83 \%$ higher in Pakistanis. In contrast, infants of mothers born in India, Bangladesh, and Africa had lower postneonatal mortality than infants of mothers born in the United Kingdom or the Republic of Ireland. Only infants of Pakistani and Caribbean mothers experienced higher postneonatal rates than those of mothers born in the United Kingdom.

The highest postneonatal rates in most categories of age, parity, social class, and birth weight were observed in Pakistani infants. Their rates across these variables were also consistently and notably higher than those for other groups of Asian origin. We could not standardise simultaneously for the maternal variables of age, parity, and social class. Standardisation for each of these variables separately, however, showed consistently and significantly lower mortality in Bangladeshi infants and higher mortality in Pakistani infants compared with the United Kingdom group. Indians and east Africans did not show significant variation. The ratio for Caribbean infants was significantly higher when adjusted for maternal age, the crude rate for this group also being significantly higher than that for the United Kingdom group. Indian, Bangladeshi, and east African infants had lower postneonatal mortality than infants of mothers born in the United Kingdom at every birth weight.

These findings seem paradoxical given that perinatal mortality from most causes was higher in immigrant groups than in the indigenous population ( $R$ Balarajan, B Botting, unpublished data). The basis for the divergence of patterns in the postneonatal period became apparent when the causes of death were examined. Sudden death from unknown causes, the main cause of postneonatal death in groups from the United Kingdom and the Republic of Ireland, occurred at half or less than half the rate in infants of Asian origin. This was true also of Pakistanis, who generally experienced much higher mortality from other causes throughout infancy. (The infant mortality in children of mothers born in Pakistan in England and Wales was $16 \cdot 6 / 1000$ during $1982-5$ compared with $9 \cdot 7$ in children of mothers born in the United Kingdom. ${ }^{3}$ ) Postneonatal mortality from respiratory diseases was also lower in Indian, Bangladeshi, and African infants; in Pakistani infants the rate was marginally higher than that in the United Kingdom group.

Although there has been much research in the United States on ethnic differences in the incidence of sudden infant death, ${ }^{11}{ }^{11}$ the subject has received comparatively little attention in Britain. The Oxford record linkage study reported a slightly higher risk of sudden infant death in immigrants from the West Indies and the Indian subcontinent combined. ${ }^{10}$ The number of immigrant mothers in the study was, however, small, and rates were not given separately for the different immigrant groups.

Comparisons with the Indian subcontinent are problematical primarily because registration systems are incomplete. Furthermore, sudden infant death has received little attention in these countries given the much heavier burden of mortality from infectious diseases. In our study the incidence of sudden infant death in Caribbean infants was similar to that in the United Kingdom group. Studies in America, on the other hand, consistently show much higher rates of 
sudden infant death in infants of Afro-Caribbean origin than in white infants, which are attributed in part to the less favourable birth weights and socioeconomic circumstances..$^{10} 11$

Although the potential for examining the incidence of the sudden infant death syndrome through death registration data is limited, we think that the patterns in this analysis of national statistics are worth noting. As the diagnosis of sudden infant death is based on a process of elimination rather than positive identification it depends on the amount and quality of information available. The Department of Health and Social Security's multicentre study of postneonatal mortality reported discrepancies between entries on death certificates about cause of death and the detailed pathological evidence available from necropsies. ${ }^{4}$ These difficulties could apply to the national data used in this study. There is, however, no obvious reason to suppose that there is an ethnic bias in certifying sudden infant deaths, and we believe that our comparisons are not seriously invalidated by the general diagnostic difficulties relating to sudden infant death. Moreover, sudden infant death is strongly associated with respiratory malfunction..$^{12}$ Before sudden death was classified as a special entity in the 8th revision of the International Classification of Diseases in 1970 most such deaths were recorded under respiratory diseases. In the Department of Health and Social Security's study necropsies showed that most of the deaths inappropriately classified as sudden infant death were due to respiratory causes. ${ }^{+}$The lower incidence in Asian infants of both the sudden infant death syndrome and deaths from respiratory diseases suggests that this is not a bias in certification, as respiratory disease is the main category used to certify sudden infant deaths when this label is not applied.

An interesting finding was that in the perinatal period mortality from the respiratory distress syndrome occurred at a lower rate in Asian infants, despite significantly higher mortality from other causes ( $R$ Balarajan, B Botting, unpublished data). This was true also for Pakistani infants, in whom perinatal mortality was $83 \%$ higher than that in the United Kingdom group during 1982-5. Deficiency and abnormality of surfactant in the lungs of victims of the sudden infant death syndrome is reported to be similar to that in children who die of the respiratory distress syndrome. ${ }^{12}$

Arguably, the generally higher mortality in Asian infants, particularly perinatally, could have claimed the lives of infants who would otherwise be at high postneonatal risk of sudden infant death. Our finding of lower mortality from respiratory causes in Asian infants throughout infancy confounds this argument.

In their review of international epidemiological findings on the sudden infant death syndrome Golding et al listed the risk factors associated with the condition. ${ }^{10}$ Asian women have fewer illegitimate births and fewer births at a young age and few of them smoke, variables associated with a lower risk of sudden infant death. On the other hand, they have a higher incidence of congenital anomalies and more of them are in social classes IV and V, variables associated with an increased risk. Sudden infant death is also associated with high parity and short intervals between births, which are both common in Pakistanis. A raised incidence of sudden infant death in low birthweight infants has been recorded in many parts of the world. Asian babies born in the United Kingdom are on average lighter than English babies but survive better at low birth weights. Gestational age, which is also correlated with sudden infant death, is lower in Asian than English babies. ${ }^{1+}$ Irrespective of these factors, the incidence of sudden infant death is low in Asian infants. These findings, against the background of higher overall infant mortality in Asians, could suggest further investigations of the aetiology of the sudden infant death syndrome.

Deaths from congenital anomalies were more common in all the Asian groups, particularly Pakistanis, in whom they were responsible for almost one third of all postneonatal deaths. The Asian groups generally, but Pakistanis in particular, showed an even higher mortality from congenital anomalies in the perinatal period ( $R$ Balarajan, B Botting, unpublished data). A detailed analysis of national data on ethnic differences in stillbirths and infant mortality from congenital malformations noted that the rate in Pakistani infants was 2.4 times greater than the average for England and Wales (R Balarajan, V S Raleigh, B Botting, unpublished data). The high rate of genetic disorders observed in Pakistani infants in Britain is attributed largely to consanguinity in Pakistani marriages. ${ }^{\text {is }} \mathrm{A}$ study of seven cities in Pakistan reported the significant contribution of consanguinity to infant and childhood mortality. ${ }^{16}$

Trends during 1975-85 show that in immigrant groups other than Pakistanis the excess postneonatal mortality of the mid-1970s has largely been eliminated. Of particular concern is that from 1981 postneonatal mortality in Pakistani infants was stable at well above that in other groups, and even in 1985 it was equal to the rate that had prevailed in England and Wales during the 1960s.

During 1985-6 infant mortality in England and Wales increased from $9 \cdot 4$ to $9 \cdot 6 / 1000$ live births, ${ }^{2}$ the first increase since 1970. The increase was attributable to a rise in postneonatal mortality (from $3 \cdot 9 / 1000$ live births to $4 \cdot 3$ ), whereas neonatal mortality remained constant. This rise put the postneonatal rate in 1986 almost on par with the rate for 1976. An increase in postneonatal mortality had already been recorded in several immigrant groups in the preceding period, 1984-5. Until rates by mother's country of birth become available for 1986 we cannot assess the extent to which immigrant groups shared in the national increase in postneonatal mortality during 1985-6. These results show the need for continued surveillance of postneonatal mortality among the different ethnic communities in this country and for further detailed research into the causes underlying the differences.

1 Office of Population Censuses and Surveys. Studies in sudden infant deaths. London: HMSO, 1982. (Studies on medical and population subjects No 45 .) Office of Population Censuses and Surveys. Infant and perinatal mortality 1986: DHAs. OPCS Monitor. 1987. (DH3 87/4.)

3 Office of Population Censuses and Surveys. Mortality statistics, perinatal and infant: social and biological factors. London: HMSO, 1982-5. (Series DH3 No 15-18.)

4 Knowelden J, Keeling J, Nicholl JP. Postneonatal mortality. London: DHSS, 1985.

5 Adelstein AM, MacDonald Davies IM, Weatherall JAC. Perinatal and infan mortality: social and biological factors 1975-77. London: HMSO, 1980. mortality: social and biological factors 1975-77. Lo
(Studies on medical and population subjects No 41.)

6 Office of Population Censuses and Surveys. Mortality statistics: cause. London: HMSO, 1982-5. (Series DH2 No 9-12.)

7 Office of Population Censuses and Surveys. Immigrant mortality in England and Wales 1970-78: causes of death by country of birth. London: HMSO, 1984 (Studies on medical and population subjects No 47 .

8 Office of Population Censuses and Surveys. Labour force survey 1984: country of birth, ethnic group, year of entry and nationality. OPCS Monitor 1985; 17 Dec:(LFS 85/1 and PP1 85/3.)

9 Office of Population Censuses and Surveys. Estimating the size of the ethnic minority populations in the 1980s. Population Trends 1986;44:23-7.

10 Golding J, Limerick S, Macfarlane A. Sudden infant death: patterns, puzzles and problems. Shepton Mallet: Open Books, 1985.

11 Black L, David RJ, Brouillette RT, Hunt CE. Effects of birth weight and ethnicity on incidence of sudden infant death syndrome. $\mathcal{F}$ Pediatr 1986;108: 209-14.

12 Milner AD. Recent theories on the cause of cot death. Br Med f 1987;295: 1366-8.

13 Hunt CE, Brouillette RT. Sudden infant death syndrome: 1987 perspective. f Pediatr 1987;110:669-78.

14 McFadyen IR, Campbell-Brown M, Abraham R, North WRS, Haines AP. Factors affecting birthweights in Hindus, Moslems and Europeans. $\mathrm{Br} \mathcal{J}$ Obstet Gynaecol 1984;91:968-72.

15 Bundey S, Roberts DF (eds). Health and consanguinity in immigran populations in Britain. Biology and Society 1988;5:12-37.

16 Shami SA, Schmitt LH, Bittles AH. Consanguinity-related antenatal and postnatal mortality in the populations of seven Pakistani Punjab cities. $\mathcal{f}$ Med Genet (in press)

(Accepted 13 fanuary 1989) 